\title{
Germany debates proper niche for blue-list institutes
}

\begin{abstract}
Munich. Time was that the only people who knew about the German 'blue-list' institutes were those who worked in them. But since reunification their number has nearly doubled, and their place in the German research scene has become the subject of acrimonious public debate.

The blue-list institutes - the name comes from the colour of paper on which the original list was printed - were created in the
\end{abstract}

\section{The distribution of blue-list institutes}

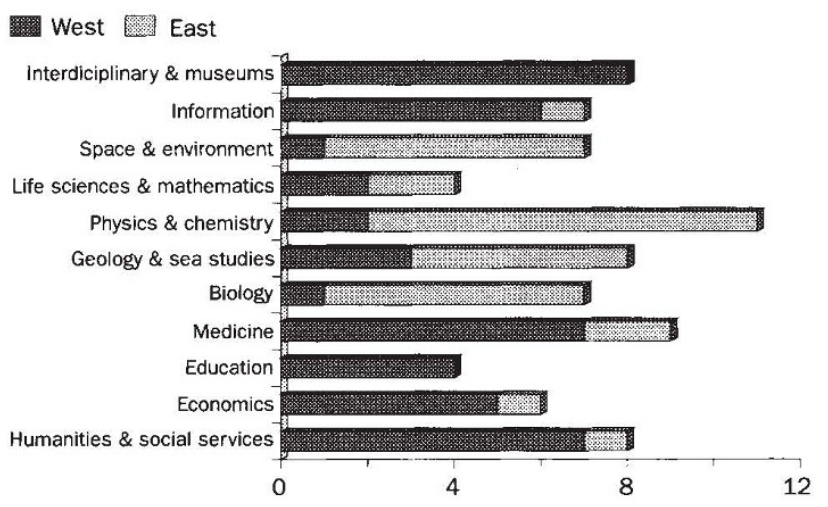

1970 s so that the federal government could help to pay for research that was of 'supraregional importance'. The three pillars of basic research in Germany - the universities, the Max Planck Society and the national research centres - argue that the 82 institutes have distorted the way that research is carried out. Only the Fraunhofer Society, whose 48 institutes undertake applied research, has remained neutral.

In 1989 there were 48 such institutes funded equally by federal and Länder governments. After reunification, the German science council, the Wissenschaftsrat, evaluated all research in the former East Germany and concluded that the new Länder should transform three institutions into national research centres and that an additional 34 should be taken over as blue-list institutes. Following their own evaluations, the Max Planck Society established two institutes and several research groups and the Fraunhofer Society established 19 institutes and branches.

At the end of 1990 , the ministry of research (BMFT) accepted the recommendations and the number of blue-list employees suddenly increased from around 5,000 to more than 9,000. In January 1991, a society (the AG-BL) was set up to look after their general interests. With a budget of DM1.16 billion (US $\$ 700$ million) - comparable to Max Planck - the institutes have become a interest."

scientific force to be reckoned with.

The appearance in a recession of a fourth 'pillar of research' has precipitated rare public discontent within Germany. The establishment, including the BMFT, says that the expanded list is inappropriate and that the research groups should conform to the existing landscape. It complains that the bluelist institutes are providing a temporary shelter for displaced researchers, that their range of topics - from the natural sciences to economics and public services such as museums and libraries - is too broad to justify a society analogous to the Max Planck Society and that a disproportionate number are located in the new Länder (see left). Their growth is contrary to the reunification treaty, it says, which gives priority to moving research from the institutes of the former East German Academy of Sciences into the universities.

Those complaints are sour grapes, says Gerhard Neuweiler, president of the Wissenschaftsrat, who believes that the debate is the result of budget cuts caused by the recession. He also believes that most institutes will retain their blue-list status after a five-year evaluation. "They were all judged by the Wissenschaftsrat to be doing valuable research typical of blue-list institutes", he says, "that is, basic research of supraregional

In response to charges that the establishment of blue-list institutes goes against the spirit of the reunification treaty, Neuweiler says that the Wissenschaftsrat recognized the impossibility of moving research straight back into universities, which were halving their staffs and which lacked the necessary

\section{ESA approves new gamma-ray mission}

London. The European Space Agency (ESA) has endorsed the proposal of its space science advisory committee to develop and launch a new gamma-ray observatory. Known as INTEGRAL (International Gamma-Ray Astrophysics Laboratory), the satellite will be between ten and fifty times more powerful than the two gamma-ray devices now in orbit. It was given top ranking two months ago by the advisory committee in a direct competition with three other proposed projects as the infrastructure for research. The special WIP programme to reintegrate a thousand individuals has foundered on these same grounds (see Nature 362, 775; 1993).

Blue-list institutes have been criticized for their inflexibility and low turnover. Unlike Max Planck institutes, they have managed to avoid changes recommended by the Wissenschaftsrat in regular assessments because of a vigorous defence of the status quo by the Länder that provide half their budgets.

However, this pattern may change under a plan to expand the responsibilities of the AG-BL. It is already setting up research sections to increase interaction among institutes and would also like to see a system that guarantees a true external evaluation and that enables resources to be shifted from weaker to stronger areas.

But that would require a single pot of money, which is politically very difficult to achieve. The federal government's share comes from at least eight ministries (the research ministry, which does not accept the concept of blue-list institutes as an organization for research, is the most important), and 16 Länder supply the rest.

To improve efficiency within the structure, the Wissenschaftsrat is considering organizing the AG-BL along the lines of the Max Planck Society, with research sections continuously evaluating standards. But AGBL board manager Wolfdieter Homann says that "we will be much more decentralized so that our institutes maintain their autonomy". Recommendations for the new structure will be announced next month, in time for consideration by the Bund-Land Kommission, which mediates between federal and Länder governments.

"In retrospect," says Neuweiler, "it is really good luck that we proposed all these institutes so early. They are the only places where science and research in the new Länder has been left undisturbed by the political upheavals."

Germany's major sponsor of basic research, the DFG (Deutsche Forschungsgemeinschaft), agrees that creating more blue-list institutes was the best interim solution for East German science but that the long-term goal should be university-based research.

Alison Abbott second 'medium-sized' project in ESA's science programme (see Nature 363, 3; 1993).

The satellite, which is being developed jointly with the US National Aeronautics and Space Administration and the Russian Institute for Space Research, will be primarily used for observing the galactic plane and centre. It is expected to cost $£ 400$ million (US\$600 million) and is scheduled to be launched - probably using a Russian Proton launcher - in 2001.

D.D. 